\title{
Early Feeding after Laparoscopic Assisted Pancreatico-Duodenectomy with Pancreatico-Gastric Anastomosis
}

\author{
K.B. Galketiya ${ }^{1}$, V.Pinto ${ }^{2}$, W.Rathnaweera ${ }^{3}$, R.Nirmalasingham ${ }^{3}$, R.M.I.M. \\ Senevirathna $^{4}$, W.E.W.M.G.W.D.N. Wijerathna ${ }^{4}$
}

\begin{abstract}
Introduction: Laparoscopic assisted pancreatico-duodenectomy (LAPD) reduces morbidity of open surgery. Enhanced recovery protocols has shown benefits from oral feeding from first post operative day. The study was done to evaluate out come with early oral feeding in patients undergoing LAPD and pancreatico-gastrostomy.

Method: Twenty two patients undergoing LAPD and pancreatico-gastrostomy were evaluated for out come after starting early oral feeding.

Results: In 22 patients studied $86 \%$ tolerated feeding from the first post operative day and the rest were fed by the third day. In $77 \%$ IV fluids were omitted by the fifth day. One patient had a prolonged drain output which settled after three weeks. One patient got readmitted after two weeks with a gastric bleed, underwent laparotomy, but died in the ICU with multi organ failure.
\end{abstract}

Conclusions: Early feeding was well tolerated after LAPD and pancreatico-gastrostomy.

Key words: laproscopy, pancreatico-duodenectomy, pancreatico-gastrostomy, ERAS

\section{INTRODUCTION}

The curative treatment for carcinoma of the peri ampullary region and head of pancreas is pancreatico-duodenectomy (PD). Considerable morbidity and occasional mortality is reported with the procedure. Long incision, handling of bowel and prolonged use of retractors can result in post operative respiratory inadequacy due to pain. Ileus can compound the problem. Blood loss is often significant. Laparoscopic assisted pancreatico-duodenectomy (LAPD) will minimize post-operative complications, which allow early discharge from hospital $(1,2,3,4,5,6)$.

The pancreatic anastomosis may be to jejunum (pancreatico-jejunostomy-PJ) or the stomach (pancreatico-gastrostomyPG). In addition there will be a choledocho/ hepatico jejunostomy and a gastro-jejunostomy. In LAPD all or some of anastomoses are performed through a mini laparotomy $(3,6)$. PG is technically easier to perform through a mini laparotomy than PJ (7). PG is equally good or better than $\mathrm{PJ}$ when post operative outcomes are compared $(8,9)$.

Traditionally oral feeding is delayed after PD for about five days. However with enhanced recovery protocols oral feeding from first post operative day one has shown benefits in many studies $(10,11)$. However there is a need for further studies (10).

\section{OBJECTIVE}

The objective of the study was to evaluate the feasibility and out come with early feeding in patients who are undergoing LAPD and PG. 
Galketiya, K. B., Pinto, V., Rathnaweera, W., Nirmalasingham, R., Senevirathna, R. M. I. M., Wijerathna, W. E. W. M. G. W. D. N., Early feeding after laparoscopic assisted pancreatico-duodenectomy with pancreatico-gastric anastomosis. Sri Lanka Anatomy Journal (SLAJ), 1(2): 28-30, 2017

\section{METHOD}

A retrospective analysis of twenty two patients who underwent LAPD at the Professorial Surgical Unit Teaching Hospital Peradeniaya from February 2014 to April 2017 was done. The resection was completed laparoscopically. in three patients hepatico-jejunostomy was performed laparoscopically and pancreatico-gastrostomy and gastrojejunostomy performed with mid line mini-laparotomy. In others, all three anastomosis were done by mini laperotomy. Oral liquids at 30ml/hour, was introduced from first day after abdominal examination. If tolerated, fluids were increased by doubling the amount daily and IV fluids were omitted when free oral intake was established. Soft solids were introduced on the third day for the patients tolerating oral liquids well. Solids were commenced by the sixth day for suitable patients. The volume of drainage from drains was measured daily. Abdominal drains were removed when drainage settled.

\section{RESULTS}

A total of 22 patients were operated, 12 being females. Age ranged from 36 to 74 . There were 12 periampullary, 1 duodenal, 4 pancreatic head, 1 uncinate process and 4 distal CBD carcinomas. In nineteen (86\%) feeding was established from next day, in two (9\%) from $2^{\text {nd }}$ and in one $(5 \%)$ from $3^{\text {rd }}$ day. In 17 (77\%) IV fluids were gradually tailed off over 5days and in other $5(23 \%)$ by the seventh day. None were started on total parenteral nutrition. In 19 cases drains were removed by the $7^{\text {th }}$ day. In two cases, by the $9^{\text {th }}$ and $10^{\text {th }}$ day. In one case, drainage persisted for 3 weeks. Oral feeding didn't increase drainage volume in any patient. One patient got readmitted with haematemesis after 2 weeks. Laparotomy revealed an unhealthy area with bleeding in the gastric fundus which was excised and sutured but the patient died in ICU after three days with multi organ failure. This brought a mortality of $4.5 \%$

\section{DISCUSSION}

PD is associated with a considerable morbidity specially with regards to pancreatic fistulas. Many techniques of pancreatic anastomoses are described including a debate about PJ and PG as well as the technique of anastomosing $(7,8,9)$. Traditionally oral feeding after PD is delayed due to multiple upper GI anastomoses. However Enhanced Recovery After Surgery (ERAS) protocols have shown that early oral feeding is well tolerated $(10,11)$.

At Professorial Surgical Unit, Teaching Hospital Peradeniya, following LAPD PG is the preferred method of pancreatico anastomosis. In twenty two patients performed during a three year period were studied about the outcome with early oral feeding. Oral liquids were started from the first post operative day after evaluating the patient and gradually increased with careful monitoring. Majority, (19/22) tolerated oral liquids from post operative day one and rest by the third day. Non required TPN or restarting IV fluids. There was a readmission after two weeks who had no problems with early feeding and was on a normal diet on discharge.

\section{CONCLUSION}

Early oral feeding was well tolerated after laparoscopic assisted pancreatico- 
Galketiya, K. B., Pinto, V., Rathnaweera, W., Nirmalasingham, R., Senevirathna, R. M. I. M., Wijerathna, W. E. W. M. G. W. D. N., Early feeding after laparoscopic assisted pancreatico-duodenectomy with pancreatico-gastric anastomosis. Sri Lanka Anatomy Journal (SLAJ), 1(2): 28-30, 2017.

duodenectomy with pancreatico-gastric anastomosis

\section{REFERENCES}

1. Gagner M, Palermo M. Laparoscopic Whipple procedure: review of the literature,J Hepatobiliary Pancreat Surg. 2009;16: 726-30.

2. Dulucq JL, Wintringer $P$, Stabilini C, Feryn T, Perissat J, Mahajna A. Are major laparoscopic pancreatic resections worthwhile? A prospective study of 32 patients in a single institution. Surg. Endosc. 2005; 19: 1028-34.

3. Lee JS, Han JH, Na GH, Choi HJ, Hong TH, You YK, Kim DG. Laparoscopic pancreaticoduodenectomy assisted by mini-laparotomy.JSLS. 2013; 17: 68-73.

4. Lei P, Wei B, Guo W, Wei H. Minimally Invasive Surgical Approach Compared With Open Pancreaticoduodenectomy: A Systematic Review and Meta-analysis on the Feasibility and Safety.Surg Laparosc Endosc Percutan Tech. 2014 [Epub ahead of print]

5. Nigri G, Petrucciani N, La Torre M, Magistri P, Valabrega S, Aurello P, Ramacciato G. Duodenopancreatectomy: Open or minimally invasive approach? Surgeon. 2014pii: S1479-666X(14)000122. doi: 10.1016/j.surge.2014.01.006. [Epub ahead of print]

6. Galketiya KB, Pinto V. The sequential pathway to the first laparoscopic resection with mini-laparotomy anastomosis for pancreatico-duodenectomy (Whipple's) in Sri Lanka, International Journal of Scientific and Research Publications 2014; 4; 1-2.

7 Masamichi M, Haruta S, Shinohara H, Sasaki K, Watanabe Pancreaticogastrostomy in pure laparoscopic pancreaticoduodenectomy-A novel pancreatic-gastric anastomosis technique BMC Surgery 2015; 15: 80.

8 Menahem B, Guittet L, Mulliri A, Alves A, Lubrano J Pancreaticogastrostomy is superior to pancreaticojejunostomy for prevention of pancreatic fistula after pancreaticoduodenectomy: an updated meta-analysis of randomized controlled trials Annals of Surgery 2015; 261: 882-7.
9 Aroori S, Puneet P, Simon R, Muiesan BP, Mayer AD, Mirza DF, Buckels JC, Isaac J. Outcomes comparing a pancreaticogastrostomy (PG) and a pancreaticojejunostomy (PJ) after a pancreaticoduodenectomy (PD) HPB: 2011; 13: 723731.

10 Coolsen MMER, Dam MV, van der Wilt,AAK. Slim,K, Lassen,C. H. C. D ejong Systematic Review and Metaanalysis of Enhanced Recovery After Pancreatic Surgery with Particular Emphasis on Pancreaticoduodenectomies World Journal of Surgery 2013; 37: 190918.

11 Kagedan DJ, Ahmed M, Devitt KS, Wei AC.Enhanced recovery after pancreatic surgery: a systematic review of the evidence HPB (Oxford) Journal 2015; 17: $11-16$.

\section{CORRESPONDENCE}

Professor K. B. Galketiya

Department of Surgery,

Faculty of Medicine,

University of Peradeniya.

Email-kbgalketiya@yahoo.com

Received: August 2017

Accepted: September 2017 